\section{Results from a Mail Survey to Assess Minnesota Vegetable Growers' Adherence to Good Agricultural Practices}

\author{
Annalisa Hultberg ${ }^{1}$, Michele Schermann ${ }^{1}$, and Cindy Tong ${ }^{2,3}$
}

ADDITIONAL INDEX wORDs. Dillman, food safety, GAPs, mailing, small farms, water, worker hygiene

Summary. To learn what areas should be emphasized in future educational good agricultural practices (GAPs) training efforts, a survey on usage of GAPs was mailed to 855 vegetable growers in Minnesota. We received a $32 \%$ response rate and a $43 \%$ cooperation rate. Over $65 \%$ of respondents reported compliance to proper worker hygiene practices, harvest container and tool sanitization and cleaning, water treatment to reduce the potential for microbial contamination, and protection of growing and stored vegetables from contamination. Small acreages and a diverse array of vegetables are typical characteristics of the majority of Minnesota vegetable farms. Seventy-seven percent of respondents farmed 15 acres or less. Most farms grew 10 or more different vegetable crops, and farmers markets, u-pick operations, and roadside stands were the most common marketing outlets. Overall responses to this study indicated that farmers currently believe they adhere to many recommended food safety best practices, but are lagging in key areas such as treating wash and processing water, taking measures to keep animals out of production fields, and cleaning and disinfecting harvesting tools and containers on a scheduled basis.

$\mathrm{F}$ ood safety related to horticultural commodities is clearly important. Fourteen percent of foodborne disease outbreaks in 2007 were due to leafy vegetables (Centers for Disease Control and Prevention, 2010). Of the 18 multistate Salmonella outbreaks reported for 2007 , spinach (Spinacia oleracea) and lettuce (Lactuca sativa) accounted for 76 illnesses, 'Beefsteak'-type tomatoes (Solanum lycopersicum) for 65 illnesses, and raw fresh basil (Ocimum basilicum) for 11 illnesses. Leafy vegetable salad contaminated with norovirus led to one of the largest number of (128) illnesses associated with a single food commodity.

In response to these outbreaks, in 2010 the U.S. Food and Drug Administration (FDA) announced a proposed rule for the safe production, harvesting,

A grant from the University of Minnesota Healthy Foods, Healthy Lives Institute provided funds for this work.

We thank Zachary Hylinski and Benjamin Tietge for helping with survey preparation and mailing, Diana Trujillo for revising graphs, and Karin Hamilton, Rhoda Burrows, and Francisco Diez-Gonzalez for reviewing drafts of this manuscript.

${ }^{1}$ Department of Bioproducts and Biosystems Engineering, University of Minnesota, 1390 Eckles Avenue, Saint Paul, MN 55108

${ }^{2}$ Department of Horticultural Sciences, University of Minnesota, 1970 Folwell Avenue, Saint Paul, MN 55108

${ }^{3}$ Corresponding author. E-mail: c-tong@umn.edu. and packing of fresh produce. The ruling is in comment period through 2011 , and a final version is anticipated to be published in early 2012 . The rule will apply to a heterogeneous industry growing many crops and on varioussized farms. Between 2005 and 2007, the U.S. Department of Agriculture's (USDA) Agricultural Resource Management Survey reported that there were 30,449 specialized vegetable and melon [melon (Cucumis spp.) and watermelon (Citrullus lanatus)] farms, generating $\approx 14 \%$ of all U.S. crop (agronomic and horticultural) cash receipts (Ali and Lucier, 2011). This survey defined a farm as "any place from which \$1,000 or more of agricultural products were sold or normally would have been sold annually," and a specialized vegetable farm is one where "vegetables and melons account for at least half of the total value of farm production." Very large farms, with a gross income of $\$ 1$ million or more per year, accounted for $87 \%$ of total vegetable crop value and are concentrated in the western United States. Small farms, with less than $\$ 40,000$ gross farm income a year, made up
$67 \%$ of all vegetable farms and are concentrated in the southern United States. Nearly 18,000 (26\%) of farms growing vegetables and melons sold their product directly to consumers (Lucier et al., 2009), resulting in $\$ 335$ million in 2007 or $\approx 19 \%$ of all vegetable and melon sales. Direct sales to consumers are increasing, up 69\% in 2007 from 2002 and up $97 \%$ from 1997. With the increased sales and increased emphasis on "buy local" and farm-to-school programs, paying attention to GAPs and food safety at the local farm level is more important than ever, especially given the July 2011 Escherichia coli outbreak in Oregon on strawberries (Fragaria Xananassa) sold at local farmers markets (Modie, 2011) and the Listeria outbreak (Centers for Disease Control and Prevention, 2011) linked to Colorado cantaloupes (Cucumis melo).

In 1998, the FDA and USDA jointly published guidelines for avoiding contamination by microbial human pathogens when producing and handling vegetables. These guidelines, titled "Guide to Minimize Microbial Food Safety Hazards for Fresh Fruits and Vegetables," have been used as the basis for GAPs audits, performed by state agencies and private companies.

Since the publication of these guidelines, various researchers have used mail surveys to understand the degree to which farmers have implemented GAPs on their farms. Rangarajan et al. (2002) surveyed 615 fruit and vegetable growers in New York, receiving 213 responses. With a response rate of $35 \%$, the respondents' farms represented $25 \%$ of all vegetable and $11 \%$ of all fruit acreage in New York. Average farm size was 250 acres, but $54 \%$ of respondents farmed less than 100 acres. Areas identified for further education included increasing awareness of outbreaks associated with fresh produce, recordkeeping of manure applications, composting processes, irrigation water quality testing, and use of sanitizers in wash water.

Cohen et al. (2005) sent out mail surveys to 609 fruit and vegetable

\begin{tabular}{llll}
\hline $\begin{array}{l}\text { Units } \\
\text { To convert U.S. to SI, } \\
\text { multiply by }\end{array}$ & U.S. unit & SI unit & $\begin{array}{l}\text { To convert SI to U.S., } \\
\text { multiply by }\end{array}$ \\
\hline 0.4047 & acre $(s)$ & ha & 2.4711
\end{tabular}


growers in six New England states, obtaining a $49 \%$ response rate. Demographic information on the growers was not included, however as with the New York growers, farmers participating in this survey did not test irrigation water or use sanitizers in wash water, and could improve record keeping. Growers also infrequently cleaned harvest containers before use or sanitized storage containers and packing equipment. Most used water without sanitizers for cleaning food processing surfaces and bare hands for packing produce. Ellis et al. (2005) interviewed nine Iowa growers of produce operations ranging in size from 1.5 to 80 acres and found that growers could improve handwashing facilities and practices, cleaning and sanitizing protocols for produce and food contact surfaces, and employee training.

After publication of the FDA and USDA "Guide to Minimize Microbial Food Safety Hazards for Fresh Fruits and Vegetables," a team of researchers at the University of Minnesota started food safety awareness education at grower conferences in Minnesota. Other educational events were held, including GAPs and food safety plan writing workshops, education and technical assistance was provided to growers, and demonstration GAPs audits were hosted for growers. To learn which areas should be emphasized in future GAPs educational efforts, vegetable growers farming in Minnesota in 2008 were surveyed by mail.

\section{Materials and methods}

The mail survey was designed with help from the Minnesota Center for Survey Research and used a modification of the total design method (Dillman, 1978). The survey was based on FDA GAPs audit questions and included nine multipart questions covering the following sections: worker health and hygiene, field harvesting and transportation, packing and storage, animals and manure, irrigation, and sewage treatment. Specific questions asked are shown in Figs. 2-6. Respondents were also asked to provide demographic information on farm size, number of employees, sales outlets, and product variety.

Mailing lists were obtained from farmers market managers throughout Minnesota, organic certifying agencies, the Minnesota Department of
Agriculture, and a few vegetable commodity organizations. Two organizations were unwilling to share mailing lists but were willing to distribute the survey to their members. Overall, surveys were sent to 855 addresses. All surveys were numbered for tracking responses. Three weeks after the initial mailing, reminder postcards were sent to addresses that had not responded. Complete surveys were remailed after another 2 weeks to non-respondents, and 2 weeks after that, tear-off postcards asking if recipients were or were not vegetable growers were mailed. Frequency analyses of mail survey responses were performed using SPSS software (version 17.0.1; IBM Corp., Armonk, NY).

\section{Results}

Eight hundred fifty-five surveys were distributed by mail. Six of the surveys were found to be duplicate mailings, 19 were undeliverable, 21

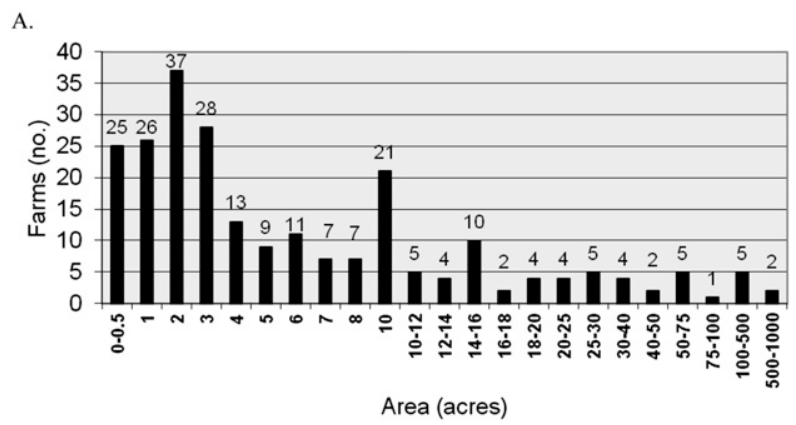

B.

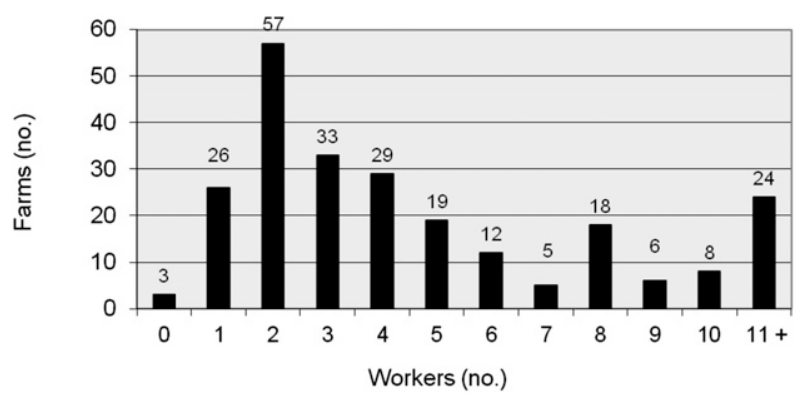

Fig. 1. Farms sizes (A) and numbers of employees (B) characteristic of respondents to a 2008 mail survey assessing adherence to good agricultural practices by Minnesota vegetable growers. Numbers above bars show the number of responses in each category. The total number of respondents for the farm size question was 237 (nine respondents left this blank) and 240 (six respondents left this blank) for the question about numbers of employees; 1 acre $=0.4047$ ha.

Table 1. Market outlets used by respondents to a 2008 mail survey assessing adherence to good agricultural practices by Minnesota vegetable growers. The question allowed respondents to mark multiple choices, so a farm may have used more than one marketing outlet.

\section{Market outlet}

Farms indicating at least some product sold to

\begin{tabular}{lc} 
Wholesale & 38 \\
Food service & 11 \\
Food co-operatives & 25 \\
Restaurants & 38 \\
Farmers markets & 185 \\
Community supported agriculture & 32 \\
U-pick and roadside stands & 80 \\
Other & 22 \\
Did not answer question & 2 \\
Total $^{z}$ & 246 \\
\hline
\end{tabular}

${ }^{2}$ Total number of farms that responded to this question. 
were partial responses, 211 were not to vegetable growers, and 14 were refusals. There were 246 completed surveys and 338 non-responses. Using the equation in which response rate $=$ completed + partial surveys $/$ (completed + partials $)+($ refusals + nonrespondents + non-vegetable growers), we calculated a response rate of 267/ $830(32 \%)$ and a cooperation rate [denominator same as for response rate but less non-vegetable growers (American Association for Public Opinion Research, 2011)] of 267/ $619(43 \%)$.

The majority of respondents had small, diverse, retail-based operations with few employees (Fig. 1A and B). The percentage of survey respondents who reported farming vegetables on 2 acres or fewer was $37 \%$, and another $40 \%$ reported farming on 3 to 10 acres. Sixty percent stated that they grew 10 or more different types of vegetables (data not shown), and $75 \%$ responded having fewer than six employees. The most frequently reported sales channel was direct marketing, with $75 \%$ of respondents reported selling their product at farmers markets and u-pick operations and roadside stands (Table 1). The top five vegetables grown by respondents were tomato, potato (Solanum tuberosum), cucumber (Cucumis sativus), pumpkin (Cucurbita pepo), and squashes (Cucurbitaceae). Leafy greens, such as cabbage (Brassica oleracea var. capitata), kale (B. oleracea var. viridis), lettuce, and arugula (Eruca vesicaria), are sold in Minnesota but are a minor part of most vegetable farm sales.

A high percentage of survey respondents stated that they followed GAPs as described in the survey questions (Figs. 2-6). With regard to worker health and hygiene, $73 \%$ to $94 \%$ of respondents stated that workers had access to clean and safe drinking water, received training on proper hygiene practices, were required to wash hands before starting work, were kept from touching vegetables if ill, and were told to get first aid treatment immediately if injured (Fig. 2). A majority of respondents agreed with the statements that harvesting containers were sanitized before use $(84 \%)$ and harvesting tools were cleaned at least once per week (67\%). Seventy-one percent of respondents stated that they had standard operating procedures for dealing with contamination of vegetables (Fig. 3).

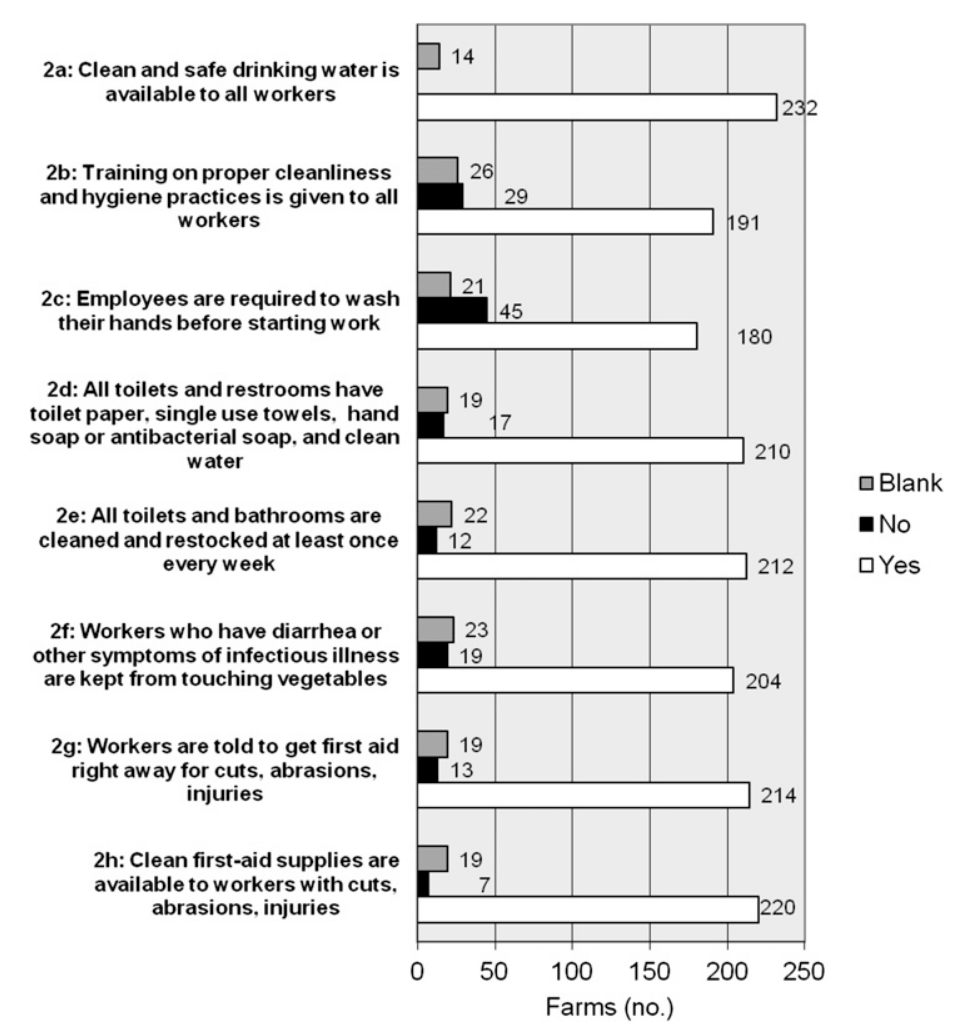

Fig. 2. Numbers of farms that replied yes (white bars) or no (black bars), or did not reply (gray bars) to various questions regarding worker hygiene on a 2008 mail survey of Minnesota vegetable growers. The number to the right of each bar indicates the number of responses for that category. The total number of farms that responded to these questions was 246.

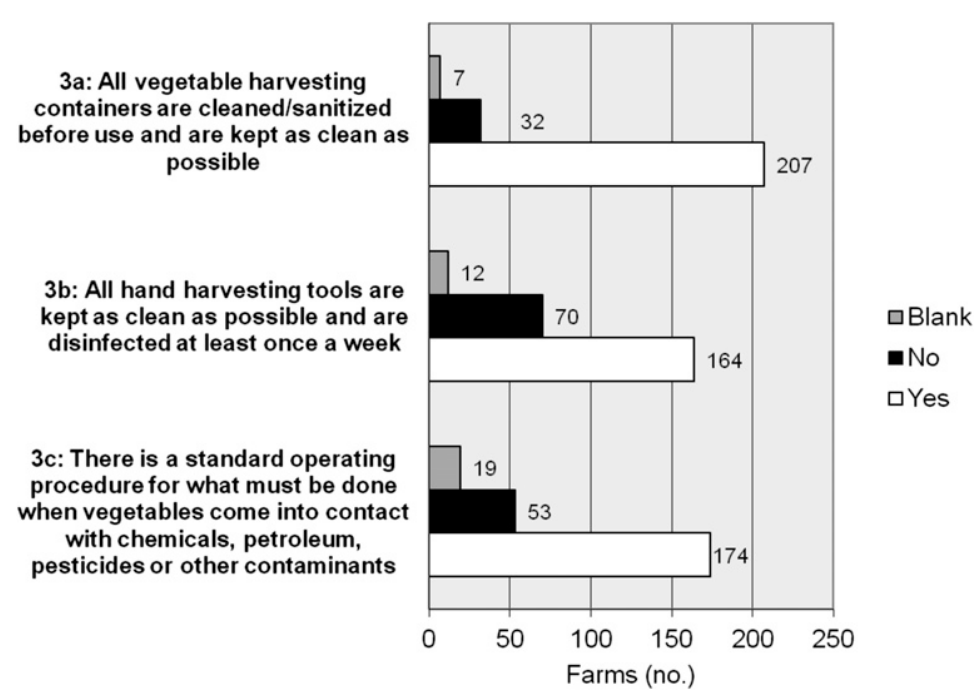

Fig. 3. Numbers of farms that replied yes (white bars) or no (black bars) or did not reply (gray bars) to various questions regarding harvest practices on a 2008 mail survey of Minnesota vegetable growers. The number to the right of each bar indicates the number of responses for that category. The total number of farms that responded to these questions was 246 .

More than two-thirds of respondents stated that they adequately treated water used for washing, storing, and processing to reduce the potential for microbial contamination; took measures to keep animals and pests out of packing and storage buildings; properly stored packing containers; protected stored vegetables from contamination; and stored 


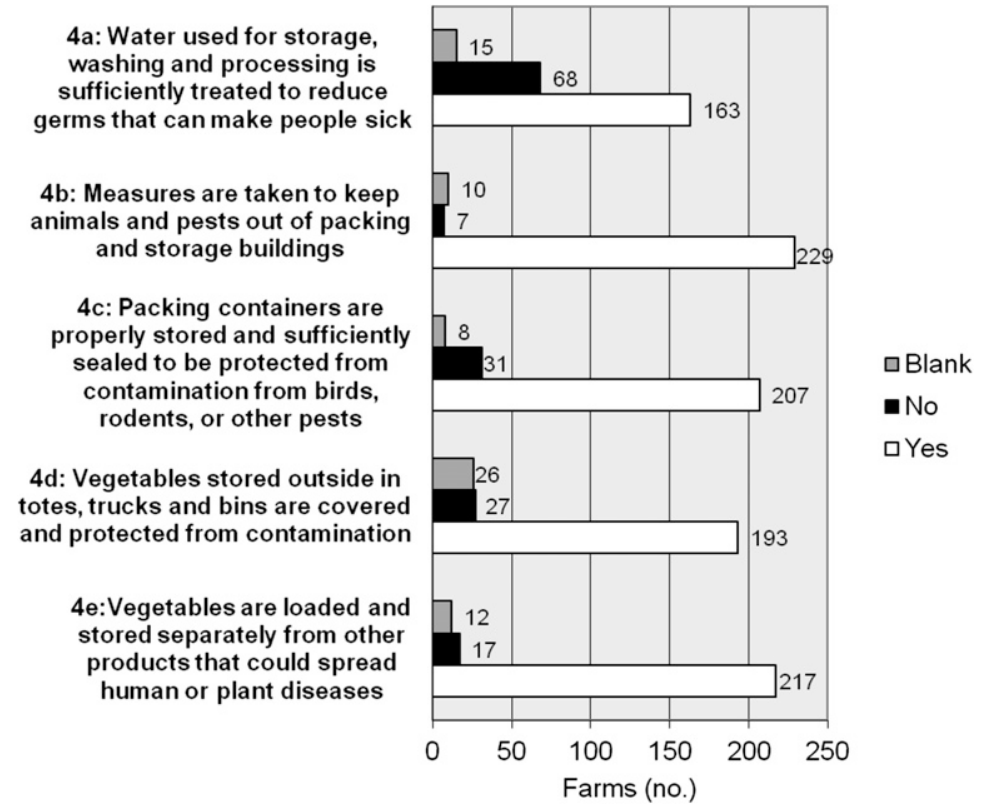

Fig. 4. Numbers of farms that replied yes (white bars) or no (black bars) or did not reply (gray bars) to various questions regarding storage and handling on a 2008 mail survey of Minnesota vegetable growers. The number to the right of each bar indicates the number of responses for that category. The total number of farms that responded to these questions was 246 .

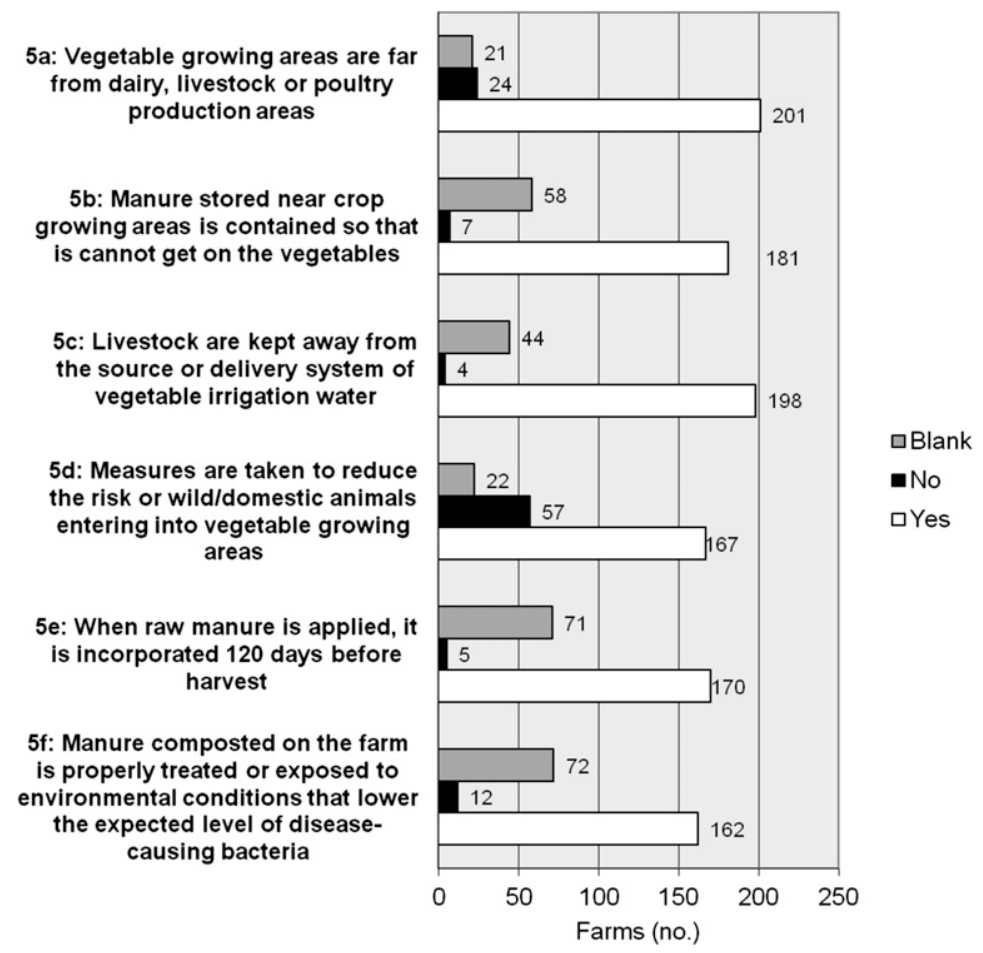

Fig. 5. Numbers of farms that replied yes (white bars) or no (black bars) or did not reply (gray bars) to various questions regarding manure and compost on a 2008 mail survey of Minnesota vegetable growers. The number to the right of each bar indicates the number of responses for that category. The total number of farms that responded to these questions was 246.

vegetables separately from products that could spread human or plant diseases (Fig. 4).
Most respondents stated that they grew vegetables far from animal production areas $(82 \%)$, contained
Table 2. Numbers of farms using various sources of irrigation water, based on a 2008 mail survey to assess adherence to good agricultural practices by Minnesota vegetable growers. The question allowed respondents to mark all choices that applied, so a farm may have used more than one irrigation method.

\begin{tabular}{lc}
\hline $\begin{array}{l}\text { Source of } \\
\text { irrigation water }\end{array}$ & Farms (no.) \\
\hline Do not irrigate & 58 \\
Pond & 10 \\
Stream & 10 \\
Well & 139 \\
Municipal & 11 \\
Other & 15 \\
Did not answer question & 3 \\
Total & 246 \\
${ }^{2}$ Total number of farms that responded to this \\
question.
\end{tabular}

manure so it could not contaminate vegetables (74\%), kept livestock away from irrigation water $(81 \%)$, took measures to reduce the risk of animals entering vegetable production areas $(68 \%)$, incorporated manure over 120 d before harvest (69\%), and treated manure and compost to decrease levels of disease-causing bacteria (66\%, Fig. 5). Twenty-four percent of respondents did not use irrigation water, $56.5 \%$ of respondents used well water for irrigation, and less than $20 \%$ of respondents used water from ponds, streams, wells, another source of irrigation water, or did not answer this question (Table 2). Sixty-six percent of respondents agreed that their "irrigation water will not spread human or plant diseases to the crop being irrigated." Most (87\%) respondents stated that they had a properly functioning farm septic or sewage treatment systems (Fig. 6).

Responses did not vary by farm size, except for questions related to toilets and restrooms [questions $2 \mathrm{~d}$ and $2 \mathrm{e}$ (Fig. 2)]. In response to the statement, "All toilets and restrooms have toilet paper, single use towels, hand soap or antibacterial soap, and clean water for handwashing" and "All toilets and bathrooms are cleaned and restocked at least once every week," the majority of responses were "yes" (Fig. 7). However, in regard to the first statement, there were more blank (did not answer) than "no" responses for farms of 0 to 2 acres, while the reverse was obtained for 


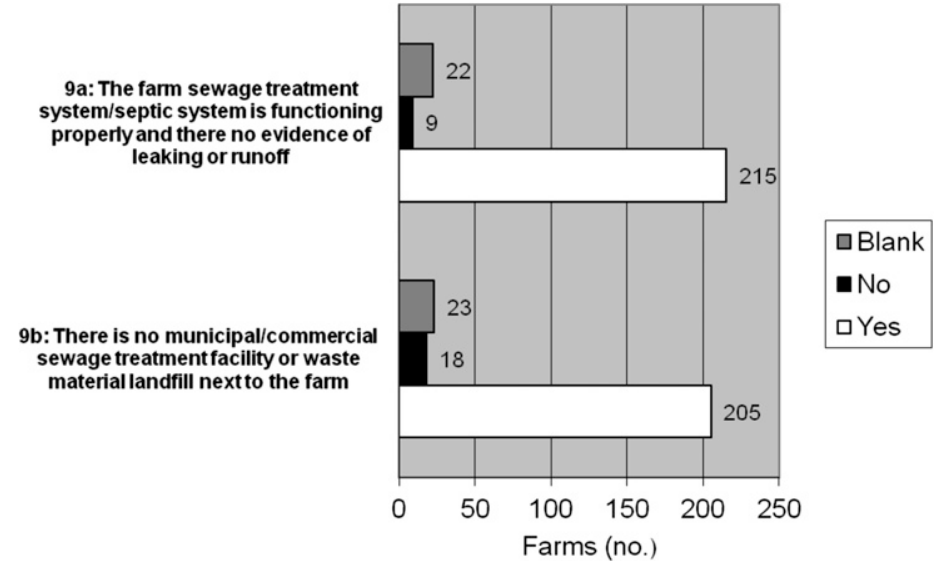

Fig. 6. Numbers of farms that replied yes (white bars) or no (black bars) or did not reply (gray bars) to various questions regarding sewage systems on a 2008 mail survey of Minnesota vegetable growers. This was question 9 of the survey. The number to the right of each bar indicates the number of responses for that category. The total number of farms that responded to these questions was 246.

\section{$2 \mathrm{~d}$ : All toilets and restrooms have toilet paper, single use towels, hand soap or antibacterial soap, and clean water for hand washing}

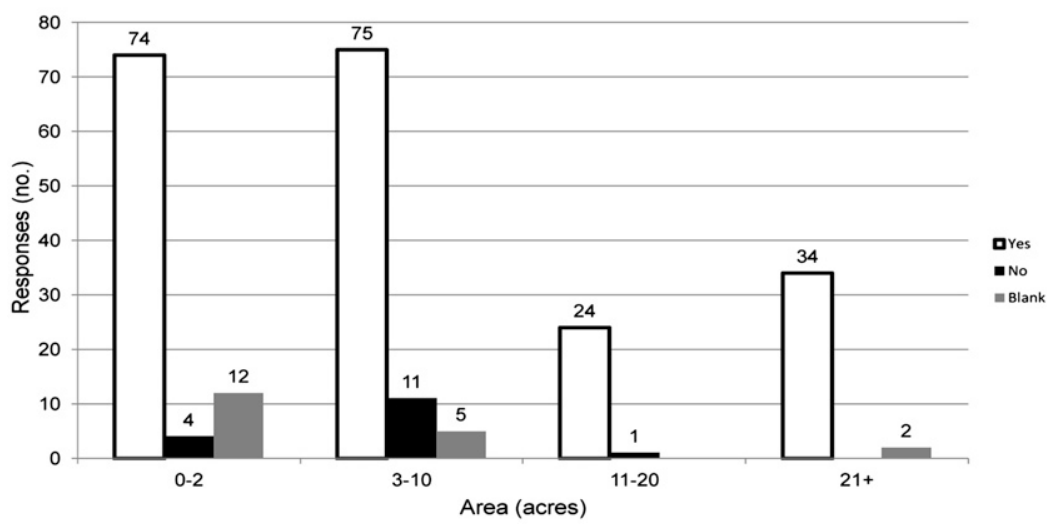

\section{2e: All toilets and bathrooms are cleaned and restocked at least once every week}

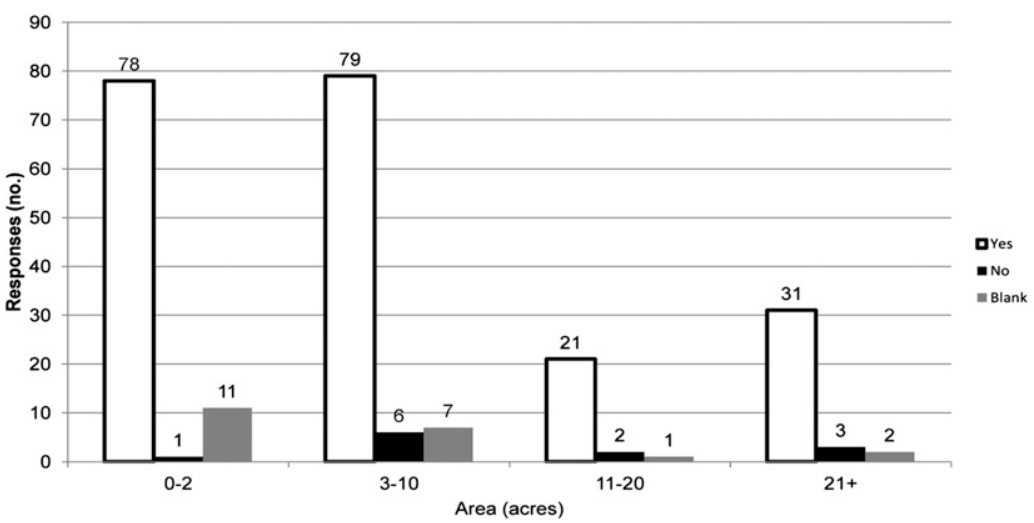

Fig. 7. Responses to questions $2 \mathrm{~d}$ and $2 \mathrm{e}$ regarding toilets and restrooms on a 2008 mail survey of Minnesota vegetable growers, sorted by farm size. The number of responses for a category is listed above each bar. White bar $=$ yes, black bar $=$ no, and gray bar $=$ no response; 1 acre $=0.4047$ ha. farms of 3 tol 0 acres. For the second statement, there were more blank than "no" responses from farms of 0 to 2 acres, and about equal blank $(n=7)$ and "no" $(n=6)$ responses from farms of 3 to 10 acres.

\section{Discussion}

According to the 2007 Census of Agriculture conducted by the USDA National Agricultural Statistics Service (USDA, 2007), Minnesota had 972 vegetable farms. With a total of 246 usable surveys collected for this study, survey respondents represented $25 \%$ of all vegetable farms estimated to exist in Minnesota by USDA. Because new farms both come into existence and disappear every year, it is difficult to locate every vegetable farm in Minnesota, especially those operated by new immigrants who often rent farmland.

The 2007 Census of Agriculture states that vegetable and melon farms in the United States are largely individually owned and relatively small, with $75 \%$ of farms of 15 acres or smaller. Survey results from Minnesota vegetable farms match that profile with $77 \%$ of respondents farming 10 acres or less. The Minnesota farms grow a diversity of crops, as $60 \%$ of survey respondents reported raising 10 or more different crops.

Although the mail survey for this research relied on self-reporting and should be validated in future work with on-farm visits, respondents reported good adherence to GAPs. However, many of the questions asked on the survey may not apply to their operations. For example, $24 \%$ of respondents did not use irrigation and $36 \%$ of them had two employees or fewer, who may be family members. We did not ask growers if they used raw manure on their farms, which may have led to the $31 \%$ of blank or no response for question $5 \mathrm{e}$. However, a validation study performed as a follow-up to this study (data not shown) showed that $\approx 60 \%$ of growers do not keep animals or manure piles, suggesting that many growers who participated in our survey do not use raw manure. Also, some questions may have led to multiple interpretations. For example, growers may keep harvesting containers and tools "as clean as possible," but not sanitize them before use, or may sanitize 
them at the beginning of the season but not every week. Growers may think they have "standard operating procedures" for dealing with contamination of vegetables, but may not realize that these should be written procedures. Based on the reported degree of practice by farmers, the greatest areas of improvement identified as lacking with this survey were treating wash and processing water, taking measures to keep animals out of production fields, and cleaning and disinfecting harvesting tools on a scheduled basis. These are practices identified in previous studies (Cohen et al., 2005; Ellis et al., 2005; Rangarajan et al., 2002), suggesting that these improvement areas are needed on farms across the United States. Although not identified as an issue by Minnesota growers, both Cohen et al. (2005) and Rangarajan et al. (2002) found that growers could improve irrigation water quality testing and record-keeping practices, thus more education and technical assistance are also needed for growers in these areas.

GAPs are important for all growers, as they can protect the health of the consumer from potential microbial contamination. Small-scale operations, such as those in Minnesota, may have difficulty implementing many of the GAPs to the extent needed to pass audits based on the time and expertise required (Hardesty and Kusunose, 2009). For small, family-run farms, passing food safety audits for 10 or more different crops will require significant time, cost, and effort, yet GAPs are important to implement regardless of size or type of operation. We suggest that for maximal adherence, guidelines should promote and encourage participation for all growers in a costeffective and feasible manner.

\section{Literature cited}

Ali, M. and G. Lucier. 2011. Financial characteristics of vegetable and melon farms. U.S. Dept. Agr. Econ. Res. Serv. Rpt. VGS-342-01

American Association for Public Opinion Research. 2011. Standard definitions: Final dispositions of case codes and outcome rates for surveys. 7 th ed. American Association for Public Opinion Research, Deerfield, IL.

Centers for Disease Control and Prevention. 2010. Surveillance for foodborne disease outbreaks - United States, 2007. Morb. Mortal. Wkly. Rpt. 59:973-979.

Centers for Disease Control and Prevention. 2011. Multistate outbreak of listeriosis associated with Jensen Farms cantaloupe - United States, August-Sept. 2011. Morb. Mortal. Wkly. Rpt. 60:13571358.

Cohen, N., C.S. Hollingsorth, R.B. Olson, M.J. Laus, and W.M. Coli. 2005. Farm food safety practices: A survey of New England growers. Food Protection Trends 25:363-370.
Dillman, D.A. 1978. Mail and telephone surveys: The total design method. Wiley, New York.

Ellis, J.D., C.H. Strohbehn, and D.H. Henroid, Jr. 2005. Assessing on-farm food handling practices of Iowa-grown produce and eggs in regard to food safety. Food Protection Trends 25:758761.

Hardesty, S.D. and Y. Kusunose. 2009. Growers' compliance costs for the Leafy Greens Marketing Agreement and other food safety programs. Univ. California Small Farm Res. Brief, Sept. 2009. University of California, Davis.

Lucier, G., R.L. Dettmann, and M. Da Pra. 2009. Direct-to-consumer sales of vegetables rising. Vegetables and melons outlook. U.S. Dept. Agr. Econ. Res. Serv. Rpt. VGS-333.

Modie, J. 2011. Fresh strawberries from Washington County farm implicated in E. coli Ol57 outbreak in NW Oregon. 8 Aug. 2011. <http://www.oregon.gov/ OHA/news $/ 2011 / 2011-0808$.pdf?ga $=$ t $>$.

Rangarajan, A., M.P. Pritts, S. Reiners, and L.H. Pedersen. 2002. Focusing food safety training based on current grower practices and farm scale. Hort Technology 12:126-131.

U.S. Department of Agriculture. 2007. 2007 Census of Agriculture. 9 Sept. 2011. <http://www.agcensus.usda.gov/ Publications/2007/Full_Report>. 